\title{
Impétigo ampolloso
}

\section{Bullous impetigo.}

Pérez-De la $\mathrm{O} \mathrm{AD}^{1}$, García-Romero $\mathrm{MT}^{2}$

\section{INTRODUCCIÓN}

El impétigo es la enfermedad infecto-contagiosa más común en la piel. ${ }^{1}$ Existen dos tipos: no ampolloso, que es el más frecuente, y ampolloso. Es causado principalmente por Streptococcus pyogenes (Streptococcus $\beta$-hemolítico del grupo A) y Staphylococcus aureus. ${ }^{1}$ El impétigo no ampolloso es producido principalmente por $S$. pyogenes y se caracteriza por vesículas pequeñas que rápidamente se rompen y originan un exudado que al secarse forma costras melicéricas. El impétigo ampolloso siempre es causado por $S$. aureus y es el resultado de la acción de una toxina epidermolítica que genera lisis entre las conexiones intercelulares de los queratinocitos formando una ampolla flácida sobre la epidermis superficial. Se clasifica en primario, que es el que tiene lugar sobre piel previamente sana; secundario, que aparece en piel lesionada, principalmente sobre piel con dermatitis o eccema. ${ }^{2}$

\section{DATOS EPIDEMIOLÓGICOS}

El impétigo ampolloso predomina en lactantes menores sin predilección por sexo. Es más frecuente en estratos socio-económicos bajos, en verano, climas tropicales y en niños desnutridos. Su frecuencia es mayor cuando hay traumatismos, picaduras de insectos, dermatosis pruriginosas preexistentes, infecciones piógenas extra cutáneas y mala higiene personal. ${ }^{1}$
${ }^{1}$ Médico pasante del servicio social en investigación. ${ }^{2}$ Médico adscrito al departamento de dermatología. Instituto Nacional de Pediatría, Ciudad de México.

Recibido: 8 de mayo del 2017

Aceptado: 31 de mayo del 2017

Correspondencia

Dra. María Teresa García Romero teregarro@gmail.com

Este artículo debe citarse como Pérez-De la O AD, García-Romero MT. Impétigo ampolloso. Acta Pediatr Mex. 2017;38(5):351-354. 
El impétigo estafilocócico, al igual que otras piodermias, se transmite de persona a persona, a través de las manos y de las secreciones nasales. Es importante identificar el estado de portador asintomático, ya que es difícil de erradicar (S. aureus coloniza las ventanas anteriores de las fosas nasales y las partes húmedas del cuerpo) y puede perpetuar el problema. ${ }^{2}$

\section{ETIOPATOGENIA}

La epidermis se compone por 5 estratos que van de profundo a superficial del estrato basal al córneo (Figura 1). Dentro de la capa basal proliferan los queratinocitos y van migrando de forma ascendente a los otros estratos. Como parte estructural de los queratinocitos se encuentran los desmosomas, que son filamentos proteicos adherentes que unen su citoesqueleto con el de otros queratinocitos vecinos. En todos los desmosomas de queratinocitos, de cualquier estrato de la epidermis, se expresa la desmogleína 1 $(\text { Dsg- } 1)^{3}$ (Figura 2).

Las toxinas exfoliativas producidas por $S$. aureus son proteasas de serina (enzimas con actividad

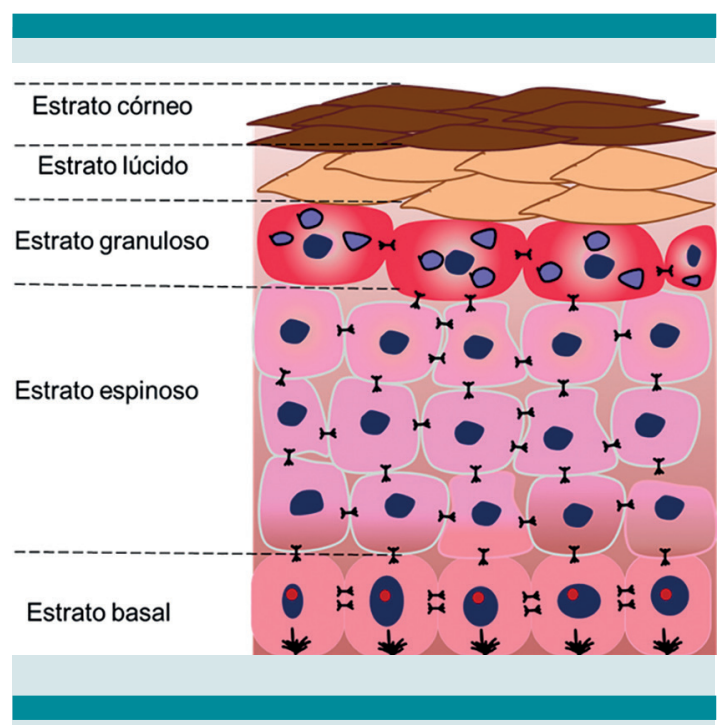

Figura 1. Estratos de la epidermis.

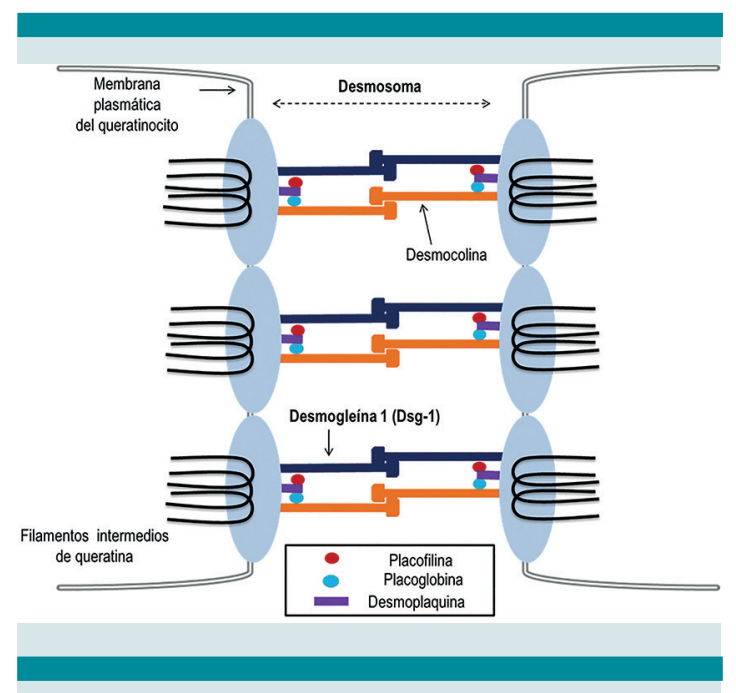

Figura 2. Desmosoma.

hidrolasa) que se unen a la Dsg-1 y alteran su función produciendo la separación entre queratinocitos o acantólisis, de esta manera, se forma una ampolla dentro de la epidermis (Figura 3).

\section{PRESENTACIÓN CLÍNICA}

La lesión inicial es una ampolla flácida sobre una piel aparentemente normal, que se rompe dejando una base eritematosa húmeda y un halo de piel que se desprende. Las lesiones secan

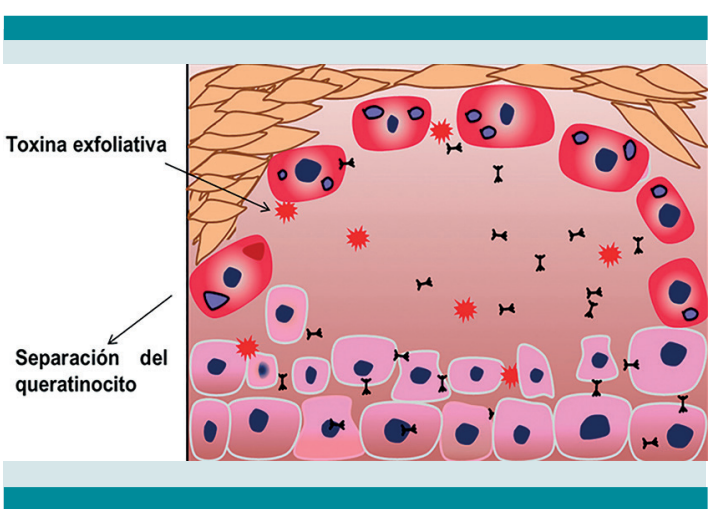

Figura 3. La toxina epidermolítica de $S$. aureus se une a la desmogleína 1 produciendo separación entre los queratinocitos generando la ampolla. 


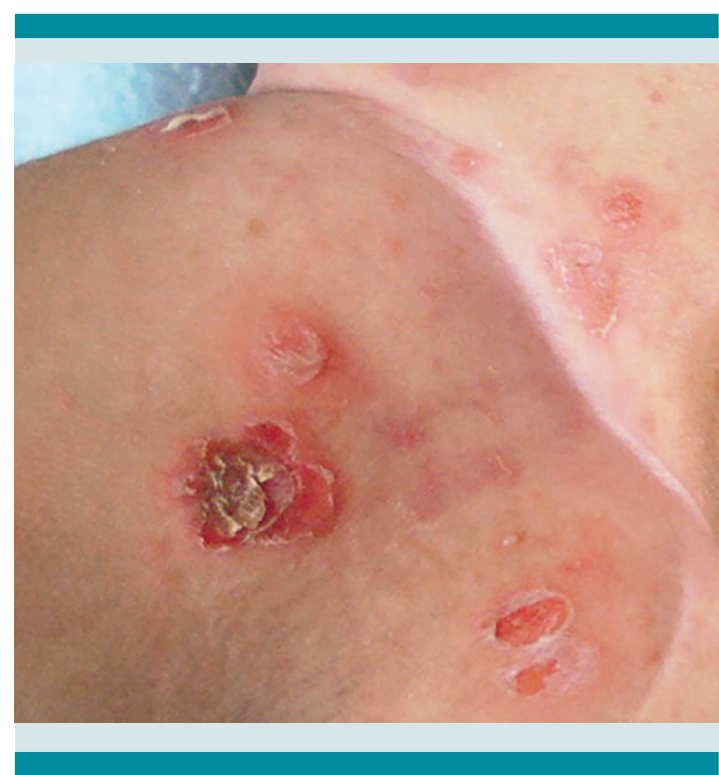

Figura 4. Ampollas producidas por las toxinas de S. aureus.

rápidamente y se cubren de costras claras, finas y superficiales (Figura 4).

Una forma clínica que se presenta en el periodo neonatal es el Ilamado pénfigo estafilocócico del recién nacido; éste puede ser grave y una posible puerta de entrada para sepsis estafilocócica, además de que tiene una elevada tasa de contagio cuando ocurre en una sala de neonatología. ${ }^{1}$

El impétigo ampolloso se considera una forma leve y localizada del síndrome de piel escaldada por estafilococo, en el cual la toxina no difunde más allá del foco infeccioso. ${ }^{1}$ Las complicaciones son raras, pero puede haber fiebre, malestar general y adenopatía regional. También puede haber síndrome de piel escaldada por estafilocócico. El grupo de edad con mayor riesgo son los lactantes mayores que ya no tienen inmunidad pasiva transmitida por la madre, pero aún no tienen anticuerpos y el aclaramiento renal de la toxina está disminuído. ${ }^{4}$

\section{ABORDAJE DIAGNÓSTICO}

El diagnóstico es clínico y sólo se realiza cultivo en agar-sangre cuando haya dudas del agente etiológico, en que se observarán cocos Gram positivos en racimo. ${ }^{2}$ El diagnóstico diferencial se hará principalmente con aquellas lesiones que presenten elevación circunscrita de la piel (Cuadro 1).

Cuadro 1. Diagnóstico diferencial

$\begin{array}{ll} & \text { Pénfigo } \\ \text { Dermatitis por contacto irritativa } & \text { Sifílides papulocostrosas } \\ \text { Diagnóstico diferencial } & \text { Tiñas inflamatorias } \\ \text { Herpes simple } & \text { Dermatitis herpetiforme }\end{array}$

\section{TRATAMIENTO}

Consiste en lavado de la zona con agua y jabón, o clorhexidina. Entre los antibióticos tópicos con mejor acción se encuentran clorohidroxiquinoleína, mupirocina, ácido fusídico y bacitracina. ${ }^{1,5}$ En lesiones extensas se recomiendan antibióticos sistémicos, como dicloxacilina, la dosis en niños es de $100 \mathrm{mg} / \mathrm{kg} /$ día. Otras alternativas son eritromicina $30 \mathrm{mg} / \mathrm{kg} /$ día $^{1}$ y cefalexina 25 $50 \mathrm{mg} / \mathrm{kg} / \mathrm{día} .^{5}$

En caso de documentarse que la infección es causada por $S$. aureus resistente a la meticilina puede utilizarse trimetroprim-sulfametoxazol en combinación con rifampicina, clindamicina, doxiciclina ${ }^{5,6}$ o vancomicina si hay intolerancia a la vía oral, su dosis en niños es $40 \mathrm{mg} / \mathrm{kg} /$ día dividido en 4 dosis $\mathrm{IV}^{7}$ sin embargo, cuando se use vancomicina siempre se debe tener la seguridad de que la infección está provocada por un $S$. aureus resistente a la meticilina ya que este antibiótico es mucho menos eficaz para las cepas de $S$. aureus sensibles. ${ }^{2}$ 
En epidemias nosocomiales en recién nacidos se requiere aislamiento y medidas generales como lavado de manos con jabones antisépticos, cultivo de muestras de piel y narinas del personal de enfermería. ${ }^{1}$

\section{REFERENCIAS}

1. Arenas Guzmán Roberto. Impétigo vulgar. Dermatología. Atlas, diagnóstico y tratamiento.4ta Edición. México. Editorial McGraw-Hill Interamericana. Año: 2009. P. 373-375.

2. Guillén Fiel, M. Santos García, N. Ureta Velasco, P. Rojo Conejo. Impétigo bulloso causado por "Staphylococcusaureus» resistente a meticilina. Acta Pediatr Esp. 2008;66(8):415-417.

3. Koji Nishifuji, MotoyukiSugai, Masayuki Amagai. Staphylococcal exfoliative toxins: "Molecular Scissors" of bacteria that attack the cutaneous defense barrier in mammals. Journal of Dermatological Science. 2008;49(1):21-31.

4. O'Connell NH, Mannix M, Philip RK, MacDonagh-White C, Slevin B, Monahan R, et al. Infant Staphylococcal scalded skin syndrome, Ireland, 2007--preliminary outbreak report. Euro Surveill.2007:12(6):E070614.5.

5. Hartman-Adams H, Banvard C, Juckett G. Impetigo: Diagnosis and treatment. Am Fam Physician 2014;90(4):229-35.

6. Bhambri S, Kim G. Use of Oral Doxycycline for Communityacquired Methicillin-resistant Staphylococcus aureus (CAMRSA) Infections. Del Rosso JQ, ed. The Journal of Clinical and Aesthetic Dermatology. 2009;2(4):45-50.

7. Dennis L. Stevens, Alan L. Bisno, Henry F. Chambers, E. Patchen Dellinger, Ellie J. C. Goldstein, Sherwood L. Gorbach, Jan V. Hirschmann, Sheldon L. Kaplan, Jose G. Montoya, James C. Wade; Practice Guidelines for the Diagnosis and Management of Skin and Soft Tissue Infections: 2014 Update by the Infectious Diseases Society of America. Clin Infect Dis 2014;59(2):e10-e52. doi:10.1093/cid/ciu296. 